\title{
Unaccompanied Children Seeking Asylum in the UK: From Centres of Concentration to a Better Holding Environment
}

\section{Jo Wilding*}

\section{ABSTRACT}

The United Kingdom's Children Act 1989 provides that unaccompanied children claiming asylum in the UK are looked after by the local authority in whose area they first come to attention of the authorities. Unlike adults, they were not subject to dispersal to other parts of the country under the Asylum and Immigration Act 1999. This has created an uneven pattern of asylum-seeker children across the country, who have no choice in where they live and are concentrated in a few geographical areas, typically near ports and administrative hubs. That, in turn, has produced unmitigated pressure on local services while fostering a view in other areas that the children are someone else's 'problem' rather than a shared responsibility for the country. This article maps the distribution of unaccompanied children in England (Different laws apply in Scotland). It considers the effects of this geographical concentration on the care of children, based on qualitative interviews with unaccompanied children and young people and adults working with them. These interviews are analysed through the lens of the requirement in the United Nations' Convention on the Rights of the Child that States must act in the best interests of the child. The support structure around each child is conceptualized as the 'holding environment' in which they live and develop, drawing on an idea developed by the British psychologist Donald Winnicott. It is argued that neither children's legal rights, nor their best interests, are best served by living in areas of high concentration. However, the article also criticizes the language of 'dispersal' and 'burden sharing' in the wider debate on refugee reception. Finally, it analyses responsibilitysharing models from France and Austria and a similar model operating between different boroughs in London, concluding that the laws and practices which exist do not fully comply with the 'best interests' principle, often because of a failure to properly fund transfer and care arrangements.

\section{INTRODUCTION}

Unaccompanied children seeking asylum face many difficulties. Jacqueline Bhabha calls them 'Arendt's children', highlighting the gap which Hannah Arendt identified between supposedly inalienable rights, on the one hand, and their enforcement in practice, on the other hand, when a 
person becomes a refugee. ${ }^{1}$ This is of course not to deny children's agency, as Elaine Chase, Ravi Kohli, and others have explored, with research coming particularly from the social work field. ${ }^{2}$ This article makes a contribution to the growing academic literature on unaccompanied children by arguing a simple point: unaccompanied children are more likely to have their needs unmet if they are left concentrated in particular geographical areas, which may therefore be unable to provide foster carers, school places, and other aspects of care because of the level of demand. This argument relies on the concept of the 'holding environment', first developed by the British child psychologist Donald Winnicott in the 1950s: I conceptualize the child's accommodation, education, social support and relationships, formal support, legal advice, and leisure opportunities as the environment which holds the child, in the absence of a family.

In the UK, section 20 of the Children Act 1989 mandates that a child for whom no adult has parental authority must be looked after by the local authority in whose area the child is found. This means that, unlike adults, unaccompanied children seeking asylum are not dispersed to other parts of the UK. This provision was intended to protect children from being sent long distances from where they arrived. As a result, however, some areas of England have responsibility for a much larger number of unaccompanied children than others.

The UK has also ratified the United Nations (UN) Convention on the Rights of the Child (CRC). ${ }^{3}$ By virtue of article 3, the child's best interests must be 'a primary consideration' both in the treatment of the individual child and in the creation of law and policy affecting children. ${ }^{4}$ The MinAs research, ${ }^{5}$ which took place from June 2014 to September 2015, sought to examine the experiences

\footnotetext{
* PhD candidate at the University of Brighton. Thanks are due to Professor Marie-Bénédicte Dembour, who supervised the research and provided many helpful comments on drafts of this article. Thanks are also due to the MinAs project partners in this research, particularly Corentin Ballieull and Ayse Dursun, for assistance with understanding the responsibility-sharing models in France and Austria. Thanks are also given to the two anonymous reviewers of this article.

${ }^{1}$ Jacqueline Bhabha, 'Arendt's Children: Do Today's Migrant Children Have a Right to Have Rights?' (2009) 31 Human Rights Quarterly 410. [Please ensure that all footnotes comply with OSCOLA styles eg this reference is now in the appropriate style for journal articles; eg include only the initial page number of the article, and, if appropriate, a pinpoint page ie the page on which the particular point or quotation occurs.]

${ }^{2}$ For example Ravi KS Kohli, 'The Sound of Silence: Listening to What Unaccompanied Asylum-Seeking Children Say and Do Not Say' (2006) 36 British Journal of Social Work 707; Elaine Chase, 'Agency and silence: Young people seeking asylum alone in the UK' (2009) British Journal of Social Work103.

${ }^{3}$ Convention on the Rights of the Child, adopted by General Assembly resolution 44/25 of 20/11/1989

${ }^{4} \mathrm{Art} 3(1)$ states: 'In all actions concerning children, whether undertaken by public or private social welfare institutions, courts of law, administrative authorities or legislative bodies, the best interests of the child shall be a primary consideration.'

${ }^{5}$ The MinAs research project was a four-State comparative study involving France, Austria, Slovenia, and the UK, and funded by the EU. Entitled 'In Whose Best Interest? Exploring unaccompanied minors' rights through the lens of migration and asylum processes.', the study investigated the application of the best interests principle set out in art 3 of the CRC across different domains of unaccompanied children's lives. A report for each of the four States and a comparative report were published in late 2015. See <http://www.minasproject.eu/> [last accessed 17 March 2017]
} 
of unaccompanied children across multiple domains - education, social support, availability of durable solutions, access to and representation in legal procedures, and so on - through the lens of this best interests principle. Since there are significant differences in law and practice between the different countries making up the UK, this paper and the research are focussed on England. For this reason, some parts of the legal framework relate to the whole UK, while other parts are specific to England.

The fieldwork for England comprised eleven semi-structured interviews with unaccompanied children and young people and seventeen interviews with adult experts working with unaccompanied children. The latter included lawyers, teachers, NGO workers and social workers in local authorities. The interview topic guides were agreed by the research teams in the four partner countries and interviews were thematically analysed with reference to a list of broad topic headings arising from the CRC, such as "experiences of education", "access to leisure activities" and so on. This paper is informed by the findings from this fieldwork and the mapping exercise set out in section two below.

The UK's dualist constitution means that the CRC does not have direct effect, since it has not been incorporated by Parliament into domestic legislation. The best interests principle has only gradually been applied to children who are subject to immigration control. The UK initially entered a reservation to the CRC which excluded such children, which it eventually withdrew in 2008 and the best interests principle was specifically incorporated into the Borders, Citizenship and Immigration Act $2009 .{ }^{6}$ Even so, the principle is not a 'trump card' in most cases: the child's best interests are $a$ primary consideration, but neither the primary nor the paramount concern as they are in public law child proceedings. ${ }^{7}$ The Children Act provision which places unaccompanied children in the immediate care of the local authority can clearly be seen as one which aims at acting in the child's best interests.

However, I argue that unaccompanied children in the local authority areas with the highest intake are disadvantaged by a lack of access to foster care, limited school places, and a stretching of support systems, including legal advice and social work support. I seek to show that it is in the best interests of unaccompanied children to be allocated promptly and taken to other areas of the UK where the Children Act responsibilities would apply in full to the receiving local authority, with any particular (informed) preferences, family ties, or religious needs of the child taken into account.

Since the MinAs fieldwork was carried out, in April to July 2015, the Immigration Act 2016 has introduced provision for the transfer of responsibility for unaccompanied children between local

\footnotetext{
${ }^{6} \mathrm{~s} 55$

${ }^{7}$ ZH Tanzania v Secretary of State for the Home Department [2011] UKSC 4 (Baroness Hale)
} 
authorities. ${ }^{8}$ Once the sections are in force, it will be possible for the Home Secretary to compel an authority to take responsibility for a child. At the time of writing, a draft protocol is in operation, enabling the transfer of responsibility. This article does not address the practicalities of the transfer scheme, but rather analyses the phenomenon that arose from the legal position at the time of the fieldwork. It describes the patterns of where unaccompanied children live in the UK, explores the effects on the young people of the uneven distribution, and discusses whether some form of responsibility sharing would be advantageous for the children. More broadly, it considers the reluctance of lower intake local authorities to take responsibility for unaccompanied children.

Notwithstanding any changes in law or practice, this phenomenon is of importance beyond its geographical and temporal context for three reasons. First, it explores the occurrence of unintended negative consequences arising from a measure intended to provide protection and how, in law and practice, such consequences can be resolved without losing the original protective intention. Secondly, it conceptualizes the whole of the environment into which a refugee or asylum seeker (child or adult) is received as a 'holding environment', ${ }^{9}$ allowing a holistic view of the person's experiences in the context of where and how he or she is received. Thirdly, it argues for the legal and policy debates about where refugees are received and accommodated to be framed in terms of 'responsibility sharing' rather than 'dispersal', or worse still, 'burden sharing'.

Regarding the latter, harsh discourses prepare the ground for the formation of harsh policies and legislation. But, equally, harsh legislation can contribute to increased public hostility. ${ }^{10}$ Hence, under the UK's dispersal scheme for adult asylum seekers, 'negatively labelled' people are deliberately placed in areas where poverty has already stretched the capacity of the holding environment. ${ }^{11}$ The policy itself seeks to reduce the financial cost of accommodating people seeking asylum, regardless of the effects on them. Reference to dispersal carries the connotation of a problem to be diluted, contributing to a climate of hostility for unaccompanied children. I argue that the term 'responsibility sharing' is preferable because it emphasizes the duty to provide care and the idea that the duty belongs to everyone, rather than being imposed by an accident of geography.

As the UK moves towards a responsibility-sharing system under the Immigration Act 2016, the best interests of unaccompanied children will only be effectively guaranteed if the lessons from previous schemes are taken into account, with a focus on the broader holding environment. To

\footnotetext{
${ }^{8}$ ss69-73

${ }^{9}$ Donald Winnicott, 'Holding and interpretation: Fragment of an analysis' (Hogarth 1986)

10 John Campbell, 'The Dispersal and Social Exclusion of Asylum Seekers: Between Liminality and Belonging' (2011) Ethnic and Racial Studies 34, 2217-8 (Review of Patricia Hynes 'The Dispersal and Social Exclusion of Asylum Seekers: Between Liminality and Belonging' (Policy Press 2011)).

11 Deborah Phillips, 'Moving Towards Integration: The Housing of Asylum Seekers and Refugees in Britain' (2006) Housing Studies 21, 539-553, at 543.
} 
support these arguments, I begin by setting out the results of the mapping exercise, showing the uneven distribution of unaccompanied children in England (part 2). I then explain in more detail the theoretical framework of the holding environment (part 3), before examining fieldwork findings in respect of children's best interests and participation when they are looked after in the highest intake areas (part 4). This helps to demonstrate the interaction between legal provisions and lived experiences. Part 5 develops the argument about the language of the debate (dispersal versus responsibility sharing) for unaccompanied children. I seek to show that the split discourse which separates asylum-seeking children from other children fundamentally influences both laws and practices towards them, contributing to the creation of concentrations. Finally, in parts 6 and 7 respectively, I analyse the lessons from previous attempts to redistribute unaccompanied children in the UK and examine a localized sharing arrangement in London, as well as responsibility-sharing arrangements in France and Austria, which illuminate the issues around responsibility sharing and holding environments. I argue that such schemes only work in children's best interests when they are well planned and properly resourced.

\section{THE MAPPING EXERCISE}

During my research on the situation of unaccompanied children in England, it became apparent that there was very little information available as to where in England unaccompanied children were living. To rectify this, I made Freedom of Information requests to all 150 local authority Children's Services departments in England to map how many unaccompanied children were looked after by each authority and how many former unaccompanied children were receiving leaving-care services. The data generated through these means provided the most comprehensive picture that currently exists about where unaccompanied children are looked after in England, even if some uncertainties remain about the findings. ${ }^{12}$

By the end of September 2015, 147 authorities had responded to my Freedom of Information requests. Of these, 30 were not looking after any unaccompanied children under section 20. Another 50 - a third of all authorities in England - had between one and nine children. The overwhelming majority - 105 in all - each looked after fewer than 20 unaccompanied children. I refer to these as low-/normal-intake authorities.

\footnotetext{
${ }^{12}$ The results may be incomplete because i) Three authorities did not respond or refused any information; ii) there may be unaccompanied children who are not in the care of a local authority; iii) There appear to be some differences in how data is recorded, eg 'unaccompanied asylum-seeking children' or simply unaccompanied minors', which may include more children; iv) where numbers are low, authorities may report them as 'fewer than five', 'fewer than ten' or 'between one and four' to prevent possible identification of individuals; v) the numbers are subject to constant change, particularly in the highest intake areas.
} 
Only seven authorities were looking after more than 50 unaccompanied children. Five of these looked after more than 100 children: Northamptonshire (104); Hillingdon, which incorporates Heathrow Airport (106); Surrey (119); the London Borough of Croydon, which houses the Home Office Asylum Screening Unit (412); and Kent which encompasses the port of Dover. The other two higher intake authorities were Essex (78) and Islington (53). These seven authorities were looking after around 43 per cent of all unaccompanied children in England.

In late April 2015, Kent was responsible for 376 unaccompanied children, having received 211 children in the period from August 2014 to early February 2015. By early September 2015, that number had almost doubled to 730. In the same period, Kent Children's Services were looking after 1,350 British children. Thus, unaccompanied children made up almost 22 per cent of the total looked-after children cohort in Kent in April 2015 and some 35 per cent by the beginning of September.

Looked at by region, London and the South East care for the highest numbers of unaccompanied children, followed by East Anglia and the East Midlands. The South West, North, North East, and North West receive very low numbers. Within each region, particularly the higher intake regions, the pattern is similarly uneven, as shown by the range for each region.

A similar mapping exercise (pre-dating the Freedom of Information Act) to this research showed that Kent was responsible for around 1,000 unaccompanied children and the London boroughs were looking after over $3,700 \cdot{ }^{13} \mathrm{As}$ is the case currently, most areas looked after fewer than 20 unaccompanied children. Three authorities besides London and Kent looked after more than 100 children each: Birmingham, West Sussex, and Northamptonshire. Eight authorities had responsibility for 50-100 unaccompanied children, and nine had between 21 and 50. Precise location patterns have shifted over time due to changing means of arrival, but the distribution curve has remained roughly the same, with most authorities in the zero-to-20 bracket.

Over time, the highest intake areas are subject to gradual falls and sudden increases which place unmitigated pressure on their capacity to provide for new arrivals. Under the Children Act system, they rely upon voluntary action by other authorities to take responsibility for any of those children.

\section{THE HOLDING ENVIRONMENT}

In conceptualizing this argument, this article borrows the concept of a 'holding environment' developed by Donald Winnicott through his work with child evacuees during the Second World

\footnotetext{
${ }^{13}$ Judith Dennis and Selam Kedane, 'Where are the Children?' (2001) Refugee Council.
} 
War. ${ }^{14}$ The holding environment refers to the multi-faceted supporting environment that gradually replaces the literal holding of a young child by a care giver. As has been shown, the quality of the holding environment is crucial to the adaptation of children migrating within families, with the emotional resources of the parents, the attitudes towards them in the host country, and the circumstances of departure, among other things, affecting the child's process of grieving for multiple losses. ${ }^{15}$

Since unaccompanied children are separated from their families, the holding environment must be constructed on arrival. Thus, in this article, I conceptualize the child's accommodation, education, social support, and relationships, formal support, legal advice, and leisure opportunities as the environment which holds the child, in the absence of a family. The holding environment, so understood, encompasses both the welfare and the liberty aspects of the child's situation and both the best interests and the participation principles of the CRC. This understanding also permits the idea that the holding environment may be strong, robust, and elastic or it may be weak, patchy, and delicate depending on its capacity (the resources available) and the number of children and young people held within it.

Although their argument does not rely on the holding environment concept, Reed and others conclude that social relationships and environment are protective factors in the psychological and emotional responses of refugee children who were resettled outside high-income countries. ${ }^{16}$ Derluyn and Broekaert discuss the psychological risks of migration in adolescence, with relief on arrival being displaced by the difficulties of integrating into a new system, culture, and language while their own identity is still forming. ${ }^{17}$ In this context, the limited support of a reception centre offering what they call 'bed-bath-bread care' is unlikely to provide a holding environment that is secure enough for the child to recover psychologically from the losses he or she has experienced.

Hanson and Nieuwenhuys conceptualize children's rights as an 'unstable translation' of underlying ideas derived from real life experience into legal principles. ${ }^{18}$ The translation is openended and reflects negotiations at a particular point in time. These unstable translations mean that it is possible for children's rights to carry contradictory meanings and for the meanings to be

\footnotetext{
${ }^{14}$ See (n 8).

15 Jennifer M. Bonovitz, 'The immigrant child', American Journal of Psychoanalysis (2004) 64, 129-41.

${ }^{16}$ Ruth V. Reed, Mina Fazel, Lynne Jones, Catherine Panter-Brick, and Alan Stein, 'Mental health of displaced and refugee children resettled in low-income and middle-income countries: risk and protective factors', (2012) Lancet 379, 250-65.

${ }_{17}$ Ilse Derluyn and Erik Broekaert, 'Unaccompanied refugee children and adolescents: The glaring contrast between a legal and a psychological perspective' (2008) International Journal of Law and Psychiatry 31: 31930, 327.

${ }^{18}$ Karl Hanson and Olga Nieuwenhuys, 'Reconceptualizing children's Rights in International Development', (CUP 2013) 3.
} 
contested. As a result, tensions or conflicts may arise between two translations. The CRC sets out a series of (more or less specific) welfare and liberty rights, underpinned by principles of best interests/protection (article 3), participation (article 12), and non-discrimination (article 2). State parties are required to legislate compatibly with the CRC. The UK's Children Act sets out more specific duties on local government which are intended to implement both the specific rights and the underpinning principles of the CRC. Yet it will be argued in this article that these rights principles may be defeated or significantly challenged by the consequences of the Children Act 1989, which has created concentrations of unaccompanied children in a few areas of the country, stretching the capacities of local governments (and local communities) to care for them.

The Children Act framework is undoubtedly beneficial to unaccompanied children and this article emphatically argues that there should be no weakening of unaccompanied children's access to the full range of rights and duties applicable to UK citizen children. This access has been hard won through campaigning and legal challenges: from 1990 when it ratified the CRC until late 2008, the UK maintained a reservation to the treaty that excluded children who were subject to immigration control. For many years, local authorities evaded their full responsibilities to unaccompanied children in order to avoid the expense of providing them with care-leaving services when they reached the age of 18. Children's rights in general, and migrant children's rights in particular, have had to be fought for despite the principle of non-discrimination. However, I argue that there are a number of ways in which children's access to their fundamental rights can be adversely affected by living in the highest intake areas of England, simply because the holding environment becomes overstretched and thus weakened.

This research was designed to explore the lived experiences of unaccompanied children across a broad range of needs and entitlements, analysed through the lens of the principle that children's best interests must be taken into account in all decisions and actions affecting them. ${ }^{19}$ It was not designed to test a hypothesis that children's access to their rights would be greater in lower intake authorities and vice versa, nor to measure the relative quality of life and care between different areas. As a result of interviews carried out in a high-intake and a normal-intake authority, however, it became apparent that there were significant differences between the areas. These were both in terms of numbers of unaccompanied young people looked after by the two authorities, and policy and practice in working with them. It began to appear doubtful whether the principle of children's best interests could be put into practice in areas where resources or the holding environment were stretched the most severely.

\footnotetext{
${ }^{19}$ UN Convention on the Rights of the Child, art 3.
} 
It is axiomatic that no children were interviewed in areas that currently do not look after any unaccompanied children. The research therefore offers no answers to the question whether it is in a child's best interests to be placed in an authority which has little or no prior experience of looking after unaccompanied children seeking asylum. On the one hand, since they are children first and foremost, any authority that has looked after children, whether British or foreign nationals, should have the required expertise to look after unaccompanied children. There clearly is a holding environment. On the other hand, as shown in the discussion of lived experiences in part 4 below, unaccompanied children have certain specific needs, such as immigration legal advice and English language support, which are unlikely to arise with British national children in local authority care. It is therefore unclear whether it would be more advantageous for a child to be placed in an authority which previously had a zero intake than in a high- or medium-intake authority.

\section{UNACCOMPANIED CHILDREN'S LIVED EXPERIENCES}

The accounts of the eleven unaccompanied children ${ }^{20}$ I interviewed for the MinAs research about their experiences in the local authority care system and the Home Office asylum-processing system was consistent with the findings of other research. They also largely aligned with the views and experiences of the seventeen adults who were also interviewed, who work closely with unaccompanied children.

Each young person's experiences span a breadth of interconnected areas. For the purposes of this article, I focus on the following aspects: accommodation (encompassing food); education, which may be categorized as welfare or protection needs; formal support; and legal representation, which may be seen as participation or liberty rights. Although other elements would need to be explored in a comprehensive discussion of the children's experiences and treatment, ${ }^{21}$ these four areas are sufficient to demonstrate that concentrations of children within limited geographical areas are likely to produce a gap between their rights on paper and the reality on the ground.

In the UK's current system, the Home Office pays a daily rate per child to the local authority to fulfil its duties. The rates change periodically but as at June 2016 the amounts were $f 95$ per day for children aged 15 or under and $f 71$ per day for those aged 16 or 17 (though from July 2016 onwards a $£ 20$ per day premium was paid to local authorities voluntarily taking on children from Kent County Council). When a child reaches the age of 18 , if eligible for care-leaving services, the local authority receives a weekly flat rate of $£ 150$, which amounts to a significant drop in funding. It

\footnotetext{
${ }^{20}$ Some were over 18 by the time of interview.

${ }^{21}$ Space does not permit a comprehensive exploration of children's experiences: refer to 'Whose Best Interest? Exploring unaccompanied minors' rights through the lens of migration and asylum processes' for further detail.
} 
is the level of funding for care-leaving services that appears to cause the greatest reluctance by UK local authorities to take on responsibility for unaccompanied children.

\subsection{Accommodation}

Children who are looked after by the local authority must be provided with accommodation. This may be in foster care, a children's home, or semi-independent accommodation with either live-in or visiting support from adults. Temporary accommodation is sometimes provided in a reception or assessment centre. Of the interviewees in this study, none had lived in a children's home, which appears to be a relatively little-used option. Foster care is sometimes considered to be infantilizing for independent adolescents migrating alone, ${ }^{22}$ and there are particular concerns in respect of private fostering arrangements rather than those overseen by a local authority. ${ }^{23}$ However, although problems can arise within foster placements, research generally suggests that foster care rather than semi-independent living is likely to be in the best interests of most unaccompanied children. ${ }^{24}$ In this research, the interviewees who had experienced foster care were almost universally positive about that experience. ${ }^{25}$ By contrast, all those who lived in semi-independent accommodation while they were children said it was difficult and they felt lonely.

One young person described how the foster family 'embraced' her, enabling her to adjust to life with them and in the UK, and to become less 'closed'. She felt part of the family, being treated as a sister by the carer's adult children, and remained in touch with them after she had moved out. Others echoed the feeling of being part of the family. Another child was fostered until the age of 16 and then had to move to semi-independent accommodation because that was the local authority's policy at the time:

The family, the whole environment, when you're with a family you have a family when you come home, family around you to talk to, hot food to eat, suddenly you're by yourself, you have to do everything by yourself, food, pay bills, many things by yourself. It would be better, absolutely, to stay with a family for longer.

\footnotetext{
22 Jacqueline Bhabha, 'Child Migration and Human Rights in a Global Age' (Princeton University Press 2014).

${ }^{23}$ Helen Connolly, "For a while out of orbit': listening to what unaccompanied asylum-seeking/refugee children in the UK say about their rights and experiences in private foster care' (2014) Adoption \& Fostering 38, 331345.

${ }^{24}$ Ala Sirriyeh, 'Hosting strangers: Hospitality and family practices in fostering unaccompanied refugee young people' (2013) Child \& Family Social Work, 18, 5-14; Laura Brownlees and Nadine Finch, 'Levelling the playing field' A UNICEF UK report into provision of services to unaccompanied or separated migrant children in three local authority areas in England (2010), UNICEF <http://www.unicef.org.uk/publications/pdf/levelling-playingfield.pdf> accessed 19 January 2016.

${ }^{25}$ Though small numbers prevent firm conclusions being drawn on this issue. See further Ravi KS Kohli, Helen Connolly and Andrea Warman, 'Food and its meaning for asylum seeking children and young people in foster care' (2010) Children's Geographies 8, 233-245.
} 
In semi-independent accommodation, this interviewee had occasional visits from a support worker and had to call the worker for help if he needed it at other times.

Further, the recognition that foster care is the optimum form of accommodation for lookedafter children and care leavers is increasingly prescribed in statute. The 'staying put' duty, which came into effect in May 2014, requires local authorities to support arrangements for the young person to remain with a foster carer beyond the 18th birthday and up to the age of 21 , if both the carer and the young person wish to do this. ${ }^{26}$ This is designed to replicate the family environment for non-looked after young people, reflecting (partly) the average home-leaving age of 24 in the general population. ${ }^{27}$

Foster care is associated not only with a family environment and a form of induction into local life, but also with relief from adult responsibilities such as budgeting, food shopping, and cooking. In contrast, one child in semi-independent accommodation described his diet as: 'Breakfast - eggs; lunch - eggs; dinner - eggs. No change'.

A best interests analysis would therefore suggest that foster care is the optimum form of accommodation, at least unless the young person expresses an informed wish to live in a different arrangement. Some local authorities stated that they aimed to place all unaccompanied children in foster care, with the expectation that they would remain there until the age of 18 and beyond. For other authorities, however, although accommodation decisions were based on an assessment of need, those aged 16 or 17 were significantly less likely to enter foster care and would generally need to show quite exceptional need in order to do so. On 3 August 2015, Kent County Council was reported in the national media to have run out of foster care spaces for new arrivals. It is perhaps obvious that, where the numbers of children are greatest, the availability of foster placements will be the most stretched and the threshold of need will be higher. While responsibility sharing does not guarantee any particular child a foster placement, nor a positive experience therein, living in one of the centres of concentration more or less rules it out.

\subsection{Education}

In the UK, education is free and compulsory up to the age of 16. In England, children must then remain in education, training, or a combination of work, education, and training between the ages of 16 and 18 . The local authority must therefore offer a school place for all children under 16 , regardless of nationality and immigration status. All schools must consider and give priority to

\footnotetext{
${ }^{26}$ Children and Families Act 2014, s98. [Please cite the full legislation in accordance with the OSCOLA notes.] ${ }^{27}$ There are debates over the best form of accommodation for indigenous children who are 'late entrants' to local authority care, so it is not necessarily the case that all UK national $16-17$ year olds would enter foster care.
} 
looked-after children, but they can decline to accept a particular individual because they do not have the resources or expertise to meet the particular child's needs. On paper, therefore, the position looks straightforward.

One child interviewed described having 'brilliant support' from the school, which provided an individual assistant for lessons, assigned other pupils to act as buddies, and used the child's Pupil Premium ${ }^{28}$ to arrange counselling. The child passed five public exams a little over a year after starting school. In another school with higher numbers of non-English speaking children, a teacher of English as an Additional Language (EAL) described a system where unaccompanied children have two to three hours per week of separate English lessons, as well as a homework club. She explained that emotional support is as important as the academic content of lessons.

Contrasting with these best practice examples, several children experienced long delays in accessing education or had long journeys to school or college. ${ }^{29}$ Two of the young people interviewed (in London boroughs) had waited 11 and six months respectively, when aged only 13. Neither received English lessons in the interim. One child (in Kent) was still waiting for a place in school or college after seven months. His age was disputed by the local authority, which believed him to be 17 , while he stated he was 15 . Delays are not unique to the higher intake authorities, but a number of children in Kent said that they were travelling for one to one-and-a-half hours each way to college in London, because there were no places available in Kent, or within the right part of Kent.

A worker from a non-government organization in Kent explained that some young people were receiving limited education from charities that taught English and life skills. He said that a number of young people in semi-independent accommodation had asked him for support accessing education, having been in the UK for several months. Frequently they did not know who their social worker was in order to get help from him or her.

A senior manager in Kent explained that a college within the county, which had previously been 'inclusive' of unaccompanied children, had stopped providing English for Speakers of Other Languages (ESOL), which meant that it no longer met the needs of the majority of unaccompanied children. The college was in an area where accommodation was more readily available and the combination of access to accommodation and education meant that a number of unaccompanied children were placed in that area. The district council began to express concern about community cohesion and the college stopped offering ESOL courses. ${ }^{30}$

\footnotetext{
${ }^{28}$ Additional money for looked-after children or those from low-income families.

${ }^{29}$ In the UK, most State-funded schools accept children up to the age of 16; those aged 16-19 mainly attend Further Education colleges.

${ }^{30}$ Public spending cuts at the time of the fieldwork were affecting English language courses around the country, but the demand among children, and therefore the impact, was greater in Kent.
} 
While the apparent decision to deliberately stop meeting the needs of unaccompanied children is unacceptable, the issues around education in Kent raise a more intractable problem: it is easy to see how 20 or 30 children, aged mainly between 13 and 17, could be absorbed reasonably easily into the educational system of a city or a county. It is much more difficult to meet the increase in demand when hundreds of new arrivals need to be placed in education. Delays in access and long journeys become inevitable.

The issues for unaccompanied children reflect those arising as a result of the dispersal of asylum-seeking families with children. Where dispersal creates concentrations, it is more difficult to find places in schools. ${ }^{31}$ As with unaccompanied children, Reakes found that the availability of (cheap) housing tended to be concentrated in certain parts of dispersal areas, so there was more pressure on school places in those areas, which might be ones with little pre-existing ethnic diversity or experience of providing EAL in schools. Dispersal is discussed in more detail in part 5 below, but it is worth noting at this point the paradox that concentrations of this sort (mainly in London and South-East England) were in part what the dispersal system aimed to avoid. Any programme for mandatorily moving people around the country needs to be carefully designed to avoid simply perpetuating the same difficulties in different places.

Given the crucial importance of schools and colleges for the children's access not only to education but also to leisure opportunities, friendships, and a community, it can be concluded that the concentration of children in a limited area is contrary to their best interests if it inhibits their access to education. Concentration is also likely to impinge on the participation aspect of rights if young people are less able to have their views and preferences about education taken into account due to the overstretching of provision.

\subsection{Formal support}

Children living outside families need support. The formal support structure for unaccompanied children seeking asylum is as follows. All looked-after children (migrant or citizen) should have an allocated social worker, an independent reviewing officer who reviews their care, and access to an advocate provided by the local authority. This advocate is not a lawyer but a person who speaks to the local authority social services on the child's behalf on particular issues at the child's request. There is also a statutory entitlement to the appointment of an Independent Visitor (IV) for any child in care for whom it would be in their best interests. ${ }^{32}$ All this is the responsibility of the local authority. In addition, all asylum seekers, including children, are entitled to free legal advice and

\footnotetext{
${ }^{31}$ Angharad Reakes, 'The education of asylum seekers - Some UK case studies' (2007) Research in Education 77, 92-107.

32 s7 and Sch.2 Children Act 1989 and s.16 Children and Young People Act 2008.
} 
representation in respect of the asylum claim and any appeal. This is provided by private firms and not-for-profit organizations under contract to the Legal Aid Agency, under the control of the Ministry of Justice. Finally, all unaccompanied children should be referred by the Home Office to the Refugee Council Children's Section - an expert charity - as a source of advice. However, three expert interviewees said such referrals were rarely made, a view confirmed by the Chief Inspector of Borders and Immigration, who reported that referrals were made in only 39 per cent of the files he sampled. ${ }^{33}$

The local authority's duty to appoint an IV was particularly conceived as a benefit for those children receiving infrequent or no visits from a parent or parental figure, which would apply to most, if not all, unaccompanied children. However, in 1998, less than a third of local authorities had an IV scheme at all. ${ }^{34}$ There are no up-to-date figures on how many authorities run an IV scheme, but none of the young people interviewed for this research said that they had an IV. One expert interviewee had attempted to be appointed as an IV for a particular young person but was informed that the authority did not have a training scheme. When the interviewee attempted to do the training in a neighbouring borough, she was refused a place because she proposed to visit a child in another borough, which had a statutory responsibility to provide its own training. At the time of interview, she had just been appointed as a 'mentor' for the young person, albeit without training and with apparently limited support. Since IVs are volunteers, it is self-evident that each authority has a limited potential supply.

The quality of the relationship with the social worker varied between the young people interviewed, as might be expected in any human relationship. One young person in a low- to normalintake authority felt her social worker was excellent. Several young interviewees mentioned low levels of support when they moved into semi-independent accommodation. Expert interviewees cited high staff turnover and great variability between social workers and social work teams, with some described as committed and caring, and others considered case-hardened and cynical. It was widely recognized that social workers were often overworked and this could have an adverse impact, for example on foster placements, the promptness of dealing with problems, access to education, or the amount of support given to the child. A foster carer praised Brighton and Hove local authority (a low- to normal-intake authority) for making efforts to ensure a good match between the foster carer and child, which had resulted in positive experiences for both. A former

\footnotetext{
${ }^{33}$ John Vine, 'An Inspection into the Handling of Asylum Applications Made by Unaccompanied Children', (2013) Independent Chief Inspector of Borders and Immigration.

${ }^{34}$ Abigail Knight, 'Valued or Forgotten? Independent Visitors and disabled young people' (1998) National Children's Bureau.
} 
social worker in another (medium- to high-intake) authority identified insufficient attention to making a good match as a cause of problems.

Most, if not all, local authorities have restructured their social work departments so that there are no longer specialist teams for asylum-seeking children. This applies even to the authorities with high numbers of asylum-seeking children. Social workers who formerly worked in specialist teams were concerned that their disbanding would lead to a loss or dilution of expertise regarding asylum, with the risk that children would not be advised of important steps or deadlines. At the same time, several interviewees, including charity workers and social workers, felt that the creation of joint looked-after children's teams dealing with both migrant and UK citizen children increased the chances of children being treated as children more than as migrants.

Of the young people interviewed, one (in Kent) did not know who his social worker was and one (in London) did not have a social worker at all as a result of an age dispute. Another child explained that his bed was broken so that it touched the ground in the middle. He was sleeping on the floor but did not know whom to ask for help in getting the bed fixed. A charity worker in Kent had 'at least five cases' where his organization was assisting children who did not know who their social worker was, which made it difficult for them to seek help. Although each of those children would have had an allocated social worker, the pressure on the social workers was such that the system was under extreme strain.

However, as the number of children arriving in Kent increased to unsustainable levels in the early autumn of 2015, it was at times impossible for new arrivals to be allocated a social worker. This reflected the position in 2001-02 when large numbers of arrivals meant that some children were placed outside Kent, despite remaining under Kent's care - a position which was recognized by all concerned as not best practice, yet the concentration made it unavoidable. As with education and accommodation, living in a low-intake area does not guarantee a positive relationship with the social worker or a good level of support, but living in a centre of concentration is likely to militate strongly against it.

\subsection{Legal representation}

Children face a complex and hostile asylum process ${ }^{35}$ Good-quality legal advice is essential to a successful asylum claim. There is evidence that poor representation can have a devastating effect on children's chances of obtaining long-term leave to remain in the UK. ${ }^{36}$ While this applies to adult

\footnotetext{
${ }^{35}$ Heaven Crawley, 'Between a rock and a hard place: negotiating age and identity in the UK asylum system' in Nigel Thomas (ed), Children, politics and communication: Participation at the margins (Policy Press 2009) ${ }^{36}$ Richard Warren and Sheona York, "How children become "failed asylum-seekers": reflections on the experiences of young unaccompanied asylum-seekers in Kent from 2006 to 2013, and how "corrective
} 
asylum seekers also, many children face additional barriers in explaining their cases which demand highly skilled representation if existing cynicism on the part of Home Office decision makers is to be overcome.

Legal aid is available to all children claiming asylum, and children's cases are funded somewhat more generously than adults' cases. Yet, when high levels of demand are concentrated in areas of limited supply, it becomes difficult to access any legal advice at all. In Kent, several interviewees stated that there were three legal aid asylum representatives: 'two good ones, one bad one'. Each firm is given a certain number of 'matter starts' on its legal aid contract, capping the number of cases it can take on in any given year, so that a certain number of asylum applicants are compelled to use the poor-quality firm. It is extremely difficult to change provider once legal aid has been granted to one provider for the case, so that even a breakdown of trust between client and representative is not usually enough for a new provider to be able to take over the case. Interviewees in Croydon likewise identified a lack of high-quality legal representation, particularly providers with expertise in children's cases.

Problems in accessing legal representation militate both for and (to some extent) against responsibility sharing. Children need to avoid long journeys to meet with their lawyers. Legal aid cuts have created advice deserts as firms have been forced to close or have withdrawn from legal aid work. ${ }^{37}$ This includes most of the East Anglia region, which has a relatively high number of unaccompanied children. This problem is not wholly unique to higher intake areas. A lawyer in a lowto normal-intake area described how, when around 15 children arrived together in a lorry, all of them were referred to her organization as the preferred legal representative for that area. The organization's size had been reduced as a result of cuts to legal aid and its ability to represent that number of children was 'stretched'. The same organization was later asked to take on some of the Kent children, despite the long journey that would involve for clients.

Thus, the problem is linked to the Children Act system in that sudden 'micro-concentrations' can also arise, which create a strain in one part of the holding environment as a result of unrelated factors such as an ill-conceived legal aid contracting system.

\section{RESPONSIBILITY SHARING, NOT DISPERSAL: THE IMPORTANCE OF} LANGUAGE IN LEGAL AND POLITICAL DEBATES

remedies" have failed them' (2014) Journal of Immigration and Nationality Law 28, 113-202

${ }^{37}$ Anne Singh and Frances Webber, 'Excluding migrants from justice: the legal aid cuts' (2010) Institute of Race Relations Briefing Paper 7. 
As indicated in the introduction, the language of these legal and political debates is significant. Harsh discourses prepare the ground for the formation of harsh policies and legislation. Bauder, for example, argues for the term 'illegalized' rather than 'illegal' to describe a migrant's status, since the latter term carries implied meanings and gives rise to emotional responses which (adversely from the migrant's perspective) affect both community relations and legal policy and decision making. ${ }^{38}$ Debates commonly revolve around 'burden sharing' and addressing a problem, a 'crisis', and an unfair share from the host area's perspective. ${ }^{39}$ Such debates risk excluding children's best interests altogether. In these circumstances, the arguments in this article risk being misconstrued and, for this reason, it is necessary both to highlight the harsh discourses at play, and to emphasize the importance of responsibility sharing for a group characterized by both vulnerability and agency, trauma and resilience, childishness and 'unchildlike' experiences.

There is a tension between the child-as-victim discourse and the migrant-as-threat discourse. ${ }^{40}$ As children, unaccompanied minors engage the welfare provisions, but as migrants they engage the political system relating to immigration policy. The unaccompanied child migrant is a threat to the construction of a child as vulnerable and apolitical. This has led Giner to describe policy on asylum-seeking children as a collision between inclusive and protectionist policies for children, on the one hand, and exclusionary policies and practices towards asylum seekers, on the other. ${ }^{41}$ From a different perspective, Crawley points out that the experiences which lead children to claim asylum are often inherently 'unchildlike' according to prevailing Western ideas of childhood - as indeed is the act of migrating alone. ${ }^{42}$ The consequence of failing to fit these assumptions about childlike behaviour is that children are treated with suspicion and disbelief, translating into a presumption that they seek access to the UK's education system rather than protection.

Unlike adult asylum seekers or children within asylum-seeking families, unaccompanied children do not face dispersal under the National Asylum Support Scheme (NASS). NASS was established by the Asylum and Immigration Act 1999 in order to withdraw access to social housing for asylum seekers who needed accommodation. Instead, they are placed in a dispersal system whereby they are transferred to one of several dispersal areas in the UK. Under this system, asylum seekers can no longer choose to live within established communities from their home country, with

\footnotetext{
${ }^{38}$ Harald Bauder, 'Why We Should Use the Term 'Illegalized' Refugee or Immigrant: A Commentary' (2014) Int J Refugee Law 26, 327.

${ }^{39}$ Vaughan Robinson, Roger Andersson, and Sako Musterd, 'Spreading the 'Burden'? A Review of Policies to Disperse Asylum Seekers and Refugees' (The Policy Press 2003)

${ }^{40}$ Giorgia Doná and Angela Veale, 'Divergent Discourses, Children and Forced Migration' (2011) Journal of Ethnic and Migration Studies 37, 1273-89.

${ }^{41}$ Clotilde Giner, 'The politics of childhood and asylum in the UK' (2007) Children and Society 21, 249-60.

42 Heaven Crawley, "No one gives you a chance to say what you are thinking': finding space for children's agency in the UK asylum system' (2010) Area 42, 162-9.
} 
adverse impacts on the wellbeing of the individual asylum seeker and the ability of refugee community organizations to support new arrivals, as well as affecting the receiving community in the dispersal area. ${ }^{43}$ Just as it can for children, the receiving community for an adult or a family seeking asylum can be conceptualized as a holding environment.

Dispersal concentrates people seeking asylum in areas of social deprivation where housing is cheap. Various authors have argued that dispersal isolates asylum seekers from communities willing and able to support them, and forces them into areas where they are perceived as competing for resources which are already scarce. ${ }^{44}$ For example, the awarding of contracts to private landlords to house asylum seekers can increase local rents, which leads to local tensions. ${ }^{45}$ Dispersal of families with children creates pressure on school places, though the available evidence suggests that asylumseeking children do not, in fact, have the presumed negative effect on schools. ${ }^{46}$ The perception of competition for resources in already deprived areas is compounded by the harsh rhetoric and policies which portray asylum seekers as threatening or undeserving and therefore an inconvenient group of people who ought to be confined to the least desirable areas. ${ }^{47}$

The academic literature has, then, already discussed the potentially adverse consequences of the dispersal system, which creates a concentration of a group of (culturally unpopular) people, such as those seeking asylum. The particular importance of dispersal to children (within families) is this: in allowing for families to be dispersed, the Immigration and Asylum Act 1999 removed the Children Act obligation on local authorities to ensure that the children in those families had an adequate standard of living. ${ }^{48}$ Local authorities were absolved of responsibility and accompanied children were left in a lower tier of protection. But this issue has received little, if any, attention in relation to unaccompanied children. This willingness to exclude migrant children from mainstream child welfare policies highlights the fragility of the buffer that the vulnerability discourse provides to

\footnotetext{
${ }^{43}$ Roger Zetter, David Griffiths and Nando Sigona, 'Social capital or social exclusion? The impact of asylum seeker dispersal on UK refugee community organizations' (2005) Community Development Journal 40, $169-81$. ${ }^{44}$ Michael Welch and Liza Schuster, 'Detention of asylum seekers in the US, UK, France, Germany and Italy: A critical view of the globalizing culture of control' (2005) Criminal Justice 5331-55; John Campbell, 'The Dispersal and Social Exclusion of Asylum Seekers: Between Liminality and Belonging' (2011) Ethnic and Racial Studies 34, 2217-8 (Review of Patricia Hynes, 'The Dispersal and Social Exclusion of Asylum Seekers: Between Liminality and Belonging' (2011) Bristol: Policy Press.

45 Deborah Phillips, 'Moving Towards Integration: The Housing of Asylum Seekers and Refugees in Britain' (2006) Housing Studies, 21/4: 539-553.

${ }^{46}$ Angharad Reakes, 'The education of asylum seekers - Some UK case studies' (2007) Research in Education No. 77: 92-107.

47 John Campbell, 'The Dispersal and Social Exclusion of Asylum Seekers: Between Liminality and Belonging' (n45); Annabelle Unity Sale (2007) 'Unaccompanied asylum seeking children: councils' reaction to dispersal proposals', <www.communitycare.co.uk/2007/03/21/unaccompanied-asylum-seeking-children-councilsreaction-to-dispersal-proposals/> accessed 6 January 2016

${ }^{48}$ Rachel Hek, 'The Experiences and Needs of Refugee and Asylum Seeking Children in the UK: A Literature Review' (2005) DFES Research Report RR635.
} 
unaccompanied children. In the case of asylum-seeking children within families, both their best interests and their participation rights are ignored, since their views are neither sought nor taken into account in the dispersal process. There is a risk that a dispersal system for unaccompanied children would likewise effectively remove them from mainstream children's services. Certainly an early proposal suggested setting up some kind of alternative provision for unaccompanied children, outside the auspices of local authority children's services, under contract with other organizations. ${ }^{49}$

Unfortunately, discussion of responsibility sharing for children in England has also thus far largely been framed as 'dispersal' prompted by a 'crisis' in a high-intake authority. In seeking to keep the best interests of each individual child at the core of these arguments, I argue that outcomes, in policy terms, would be more positive for all people seeking asylum if debates were framed around the dignity of each person, rather than around the 'burden' which they represent to the host country or area.

\section{RESPONSIBILITY-SHARING ATTEMPTS IN THE UK}

Thus far, this article has looked at the concept of the holding environment, the occurrence of concentrations of children in certain geographical areas in England, and the consequences for children within those areas. On this basis, I have argued that it is not in the best interests of children (including their participation rights) to be looked after in an area with a very high concentration of unaccompanied children. However, as argued in part 5, the UK's current dispersal system for asylum-seeking adults and families also creates concentrations and does not respect children's best interests. Therefore, the focus of my argument now shifts to the solution. There have been previous occasions when attempts have been made to address this issue in the UK, and this section considers those arrangements for sharing responsibility, with a view to analysing the factors that do or do not help to create good holding environments.

\subsection{The Pan-London Protocol}

The only ongoing example in England of responsibility sharing is in London, where the Pan-London Protocol (also called the London Boroughs Rota System) determines where children should be looked after if they come to first attention at the Asylum Screening Unit (ASU) in Croydon. ${ }^{50} \mathrm{FOI}$ data showed that the numbers across London are extremely uneven, ranging from 10 (Camden) to 412 (Croydon). The mean is 44.9, while the median is 27. Apart from Croydon, Hillingdon (106), and

\footnotetext{
${ }^{49}$ Unpublished policy proposal, November 2015

${ }^{50}$ London Asylum Seekers Consortium, 'Provision of Emergency Accommodation for Rota Referrals' and see 'Procedures Online' for any of the London boroughs, eg. http://enfield.proceduresonline.com/chapters/p_unacc_asylum.html
} 
Islington (53), all boroughs look after fewer than 50 unaccompanied children. Three boroughs have numbers in the forties, six in the thirties. This suggests that the rota is not particularly effective in sharing responsibility between boroughs.

This is partly because the rota only applies to unaccompanied children aged $16-17$. Around one-third of unaccompanied children are aged 15 or under, and therefore go straight into the care of Croydon. This would include children who were initially thought to be 15 or less but who are later assessed (by Croydon) as being 16 or 17. Interviewees explained that the rota also excludes those who come to the attention of police or social services first, rather than independently arriving at the ASU. Croydon then assumes responsibility under the Children Act before the Pan-London rota comes into play.

Best interests receive scant consideration: children are allocated to the next borough on the list, regardless of issues such as the availability of foster care, education places, the existence of a community from the child's religious or language background, the number of children that borough already looks after, or the borough's size or relative wealth. One interviewee explained a further concern that, although children should be rapidly allocated to the host borough, spending no more than five days in emergency accommodation, administrative delays can lead to them remaining in bed and breakfast accommodation without proper support for longer periods.

\subsection{The Kent Safe Case Transfer pilot programme}

In 2002, a spike in the numbers of unaccompanied children led to the creation of the Kent Safe Case Transfer pilot programme. The scheme began when Kent appealed to other local authorities to take on responsibility for some of the children. The receiving authorities were three Greater Manchester authorities..$^{51}$ The pilot programme applied only to healthy boys aged 16 or 17 who had no family ties in the South East and were willing to go. In all, 30 children were transferred from Kent to the Greater Manchester authorities over six months.

The evaluation of the pilot programme notes that the three-year funding arrangement for the scheme was much higher than the standard per capita grant. ${ }^{52}$ The receiving authorities offered a high-quality package including accommodation and education, which could not at the time be offered in Kent due to resource pressures. This led to some tensions as the boys were perceived to be receiving more support than UK citizen looked-after children. Even so, the evaluation concluded that the project was highly successful and provided a model for service development for

\footnotetext{
${ }^{51}$ Thirteen authorities initially responded to the appeal.

${ }^{52}$ Charles Watters and K. Robinson, 'An Evaluation of the Safe Case Transfer Pilot Project' (2006) University of Kent.
} 
unaccompanied children, with a number of best practice points noted. In each area, a high level of well-integrated care was provided.

By the end of the scheme, a local authority circular in 2003 and a court decision ${ }^{53}$ had clarified the responsibilities of local authorities under the Children Act 1989. Authorities now had to accommodate and look after children under section 20 of the Act, instead of providing a much lesser service under section 17 . This meant children were unequivocally entitled to receive care-leaving services when they reached the age of 18 , which was a significant, and hard won, advantage. However, since the Home Office did not fund unaccompanied care leavers at a level that local authorities considered adequate, other authorities were generally no longer willing to take responsibility for unaccompanied children from Kent. ${ }^{54}$ Thus, funding was the reason for both the pilot programme's success and its non-continuation.

\subsection{The Specialist Authorities model}

A further attempt to redistribute responsibility was developed in 2007, when the Home Office proposed that 50-60 local authorities would become 'specialist authorities', each looking after around 100 children. These were expected to be mainly outside London and the South East, mirroring the adult dispersal scheme. The proposals were said to address the 'need for a more rational system' ${ }^{55}$ Among the 'problems' the government expected to address was that some local authorities were supporting young people whom they were not legally obliged to support, rather than the concern that the best interests of unaccompanied children in high-intake areas could not be implemented.

Both this initiative and the safe case transfer pilot scheme discussed above were largely the result of extensive lobbying by Kent for the rest of the country to take on some responsibility for unaccompanied children, or to increase the funding available for Kent, particularly to cover the careleaving costs. The proposals did not come to fruition because no authorities bid to become specialist authorities. No additional funding was to be made available to specialist authorities to carry out the statutory duties placed upon them. Rather, the government expected to reduce care-leaving costs for local authorities by measures such as granting shorter periods of temporary leave to children, not granting temporary leave to those aged 16 or more, and engineering a situation where children were already removable from the UK as soon as they reached 18. It is far from obvious that the government had given any consideration at all to the best interests of the child principle, in

\footnotetext{
${ }^{53} R$ (on the application of Berhe and others) v London Borough of Hillingdon [2003] EWHC 2075 (Admin) often referred to as 'the Hillingdon judgment'.

${ }^{54}$ Annabelle Unity Sale, 'Unaccompanied asylum seeking children: councils' reaction to dispersal proposals' (n48)

${ }^{55}$ Borders and Immigration Agency, 'Better Outcomes: The Way Forward. Improving The Care Of Unaccompanied Asylum Seeking Children' (2008) BIA Communications Directorate.
} 
conceiving a system where 16- and 17-year-olds would be left in two years of limbo for the sake of cost saving and administrative convenience.

\section{COMPARATIVE ANALYSIS: FRANCE AND AUSTRIA}

The UK is not alone is receiving unaccompanied children and needing a rational system for organizing their care in a way that addresses and implements children's best interests. It is useful to look at the experiences of other refugee receiving countries, and indeed it is one of the benefits of comparative research (such as the MinAs project) that it enables this. The primary conclusion that can be drawn from such comparative analysis, however, is that any scheme that is not properly resourced and firmly grounded in an understanding of the best interests principle will fail to deliver outcomes in a child's best interests.

France has experienced similar patterns of concentration in certain areas, particularly Paris, Lille, and Marseille. The French government has attempted to address this but has so far been largely unsuccessful. In 2013, a reception protocol was issued by a Circular from France's Ministry of Justice whereby central government provides funds for five days in which to assess whether a person is a child and unaccompanied. Those assessed as children are allocated by the Children's Judge to one of 96 local départements, which must 'care-in' the child.

Serious problems quickly arose with the protocol. First, central government pays the department only for the first five days, during which the young person is assessed. After that, the full cost of caring for children is borne by the département. It frequently takes many months for the young person's age and status to be assessed, not the five days allowed for by the protocol, and children are sometimes left to live on the streets or in informal fostering arrangements. Others are given accommodation, but little attention is paid to their needs because they are expected to be transferred elsewhere in due course. These long delays in assessment mean that those who are eventually 'cared-in' have often begun to form a private life and an informal support network in the département where they are assessed. They are then transferred to the allocated department without the child's opinion or best interests being taken into account.

Secondly, the protocol, although ostensibly compulsory rather than voluntary for the départements, was issued by Circular and does not have the binding force of an Act of Parliament. In consequence, some departments refused to implement the protocol and suspended reception of unaccompanied children, arguing that they did not have the financial resources to care for them and that the money should come from the central government. By the beginning of 2014, nine départements had suspended reception procedures and 12 had appealed against the protocol. The Administrative Court ruled against the départements which suspended reception. In response to the 
departments' appeal, the Council of State (Conseil D'Etat) approved the majority of the Circular on 30 January 2015, but has asked the government to put the measures into legislation so that they are legally binding.

A further problem is that each department has a quota for the number of unaccompanied children it must accept, based on the size of its existing under-19 population. Three months after the protocol was implemented, 61 of the 96 départements had already reached their annual quota of unaccompanied children. The quotas were based on a significant underestimate of the numbers of unaccompanied children entering France. On some occasions, this has meant that a département which has reached its quota has to care for a child temporarily until an alternative allocation is made, creating more delays and uncertainty for the child.

Worse still, some children face a 'double assessment' when the allocated département refuses to accept the assessment of the first. In some cases, the child has been accepted to be a child by the first département, allocated to a second département, reassessed as an adult by the second département (though in fact this is unlawful), transferred back to the first, where the case was considered by the Children's Judge, and the child was then allocated to the first département. The prolonged uncertainty is very clearly not in the child's best interests.

Austria experiences a different pattern of concentration because asylum seekers are accommodated in one of three initial reception centres funded and operated by the federal government, or Bund. Responsibility for unaccompanied children initially rests with the Bund before being delegated to one of the nine regional governments (Länder) after they are admitted to the asylum procedure. Allocation is according to a 'distribution key' (Verteilungsschlüssel) and legal responsibility passes to the Land's Child and Youth Welfare Services.

As in France, one of the main tensions between the Bund and the Länder is funding. Once responsibility is delegated to the Länder, it is the Länder that funds care. Daily rates are set out for the care of unaccompanied children, but they are lower than the rates for UK citizen children in care, which appears to be possible only because Austria continues to apply a reservation to the CRC. ${ }^{56}$ The tension between the Bund and the Länder over funding for discharge of these responsibilities can result in delays in offers of accommodation to unaccompanied children. Children commonly stay two to three months in the reception centre at Traiskirchen, which receives all of the unaccompanied children, but it can be longer because of these delays. Perhaps partly as a result, Traiskirchen is criticized as overcrowded but also as lacking any infrastructure at all for children, with long queues for food and no provision for education. In addition, although children are entitled to have a legal guardian appointed, this cannot be done until they are allocated to one of the Länder. During that

\footnotetext{
${ }^{56}$ [This has already been noted. This $\mathrm{fn}$ can be deleted.]
} 
time, they have only a legal adviser, not a legal guardian who can make decisions on their behalf and assess their best interests.

It is clear that the most significant problem with both France and Austria's responsibilitysharing arrangements is funding. In both cases, disputes between local and central authorities cause delays or refusals to receive and care for unaccompanied children, creating periods in which children's needs are not met. Whether the arrangement is fully embedded in statute, as in Austria, or the hybrid compulsory but non-legally binding system as in France, a failure to properly fund the authority to which care is delegated causes disruption to the arrangements.

This reflects the lessons from the UK: the Kent Safe Case Transfer pilot programme, the only properly resourced scheme, is the only successful example of responsibility sharing to date. However, the reluctance to take responsibility for unaccompanied children, like the reluctance to properly fund their care, and the suspicion with which their asylum applications are viewed, suggests a broader failure to honour the spirit of the CRC where migrant children are concerned.

\section{CONCLUSION}

This article used Winnicott's concept of the holding environment as a useful framework for analysing the care and processing of unaccompanied children seeking asylum in England. It concludes that, while overall the Children Act framework is beneficial, there are unintended negative consequences that to some degree place the legislation in conflict with the CRC.

As a result of the Children Act, certain local authorities have become responsible for much higher numbers of unaccompanied children than others. Not only the overall numbers, but also any sudden increases in numbers, are concentrated in these areas. This research supports a concern that these concentrations overstretch or damage the holding environment for unaccompanied children: pressure is placed on accommodation, education places, social worker support, the capacity of legal representatives, the ability of voluntary organizations to provide social support, and so on. As a result, the concentration impinges on both the implementation of what is in children's best interests, and on their right to participate effectively in decisions affecting them.

The research discussed in part 5 above on the NASS dispersal system for adults suggests that, so long as it is treated as a mechanism for removing asylum seekers from mainstream society into the cheapest accommodation available (sometimes regardless of whether it is habitable), it deprives them of access to community and linguistic support and other services, and creates division and hostility within local areas. This research suggests that similar conclusions can be drawn with respect to the Children Act system: so long as it operates to concentrate children in certain areas, 
absolving other authorities of responsibility, it will deny some children the full benefit of the best interests principle. Yet the clear and constant theme throughout the comparison of actual and proposed responsibility-sharing models for children is that such models do not succeed without proper funding. Whether they are voluntary or compulsory schemes, the evidence shows that regional and local authorities will refuse to take on responsibilities that are likely to create a financial deficit.

Drawing on Hanson and Nieuwenhuys' conceptualization of child rights as an open-ended endeavour to translate underlying ideas from principles and lived experiences into law, ${ }^{57}$ I argue that there is a need to translate this recognition into law. However, any such translation carries a significant danger for unaccompanied children: since their access to the full benefit of the Children Act framework has been hard won, there is a difficult balance to be struck in seeking any alteration to that framework. Importantly, however, the localized nature of the Children Act obligations also enables the UK government to abdicate responsibility for these children, paying sums of money that are not commensurate with the duties which it places upon local authorities.

${ }^{57}$ See (n 17). 